\title{
A new approach of the design process for replacing wooden parts of furniture
}

\author{
Cornel Ciupan ${ }^{1 *}$, Emanuela Pop $^{1}$, Ioan Filipp $^{2}$, Emilia Ciupan ${ }^{1}$, Emilia Câmpean ${ }^{1}$, Ioan \\ Cionca $^{2}$ and Vasile Heres ${ }^{2}$ \\ ${ }^{1}$ Technical University of Cluj-Napoca, Memorandumului street, nr. 28, 400114 Cluj-Napoca, Cluj, \\ Romania \\ ${ }^{2}$ TAPARO SA, 43562 Sat Borcut nr. 98, jud. Maramures, Romania
}

\begin{abstract}
Based on different design processes for innovative products, the paper presents a new approach of the process. The new method studies the problem of replacing the wooden components of the resistance structure of furniture with other materials. This is a reverse engineering process, that starts with the entire component, following a series of steps to the part drawings, ready for manufacturing. The method was validated by redesigning some parts of the upholstered products manufactured by TAPARO Company, by replacing the wooden parts of the resistance structure of sofas with composite material.
\end{abstract}

\section{Introduction}

Innovation is an important pillar in the new product development, in an dynamic and competitive market, because the products have to meet a wide range of needs related to quality, cost, shape, visual appearance and ability to express to the user the objectives for which it was designed [1].

Creativity is needed to create innovative products and most creative ideas in the new product development process occur in the conceptional design phases [2]. For long-term growth and to remain market competition, companies need to be able to develop continuously and come up with innovative solutions to meet some needs $[3,4]$.

In addition to generating ideas and innovative solutions, new product development also involves companies' ability to apply suitable problem-solving methods to solve design problems, technology issues, etc. and also to analyse them in detail. The techniques and methods applied to solve and analyse problems, as well as to generate solutions studied in $[2,5,6]$ are Axiomatic Design (AD), Quality Function Deployment (QFD), Failure Mode Effect Analysis (FMEA) and Total Quality Management (TQM) for problems analysis and for idea generation, Brainstorming, Heuristics, Mindmapping and TRIZ [7, 8]. The paper [2] proposes a hybrid-compact design matrix model that integrates problem analysis as well as generating ideas into the early stages of new product development (NPD) process, into the conceptual design stage.

\footnotetext{
* Corresponding author: cornel.ciupan@muri.utcluj.ro
} 
These aspects explain, on the other hand, why the NPD process is complex and involves a close collaboration between the industrial designer and engineering designer [9]. KwanMyung and Kun-pyo [9] presents four types of typical collaborative product design process, identificated after interviews with industrial and engineering designers from 6 consumer product manufacturers. Currently there are various methods of NPD, some of them approach design in terms of environmental impact, functions, design and aspect, product recyclability, etc.

The exponential growth of the consumer market forces companies to be as innovative as possible, but also consider the environmental impacts, the origin of raw materials, the energy involved in the production process, transport, the way in which products are used and what happens with them at the end of their life cycle $[10,11,12]$. A new product from the customer's point of view should look good, have a reasonable price, be qualitative, be environmentally friendly and recyclable, and from manufacturer vision it have to be achieved as soon as possible, with affordable technologies and minor resource losses.

All these aspects are planned from the early stages of the NPD process and require a systematic approach of the processes, involving several phases, needs identification, task clarification, conceptual design, part design and the assembly [13]. Darian [10] presents in his study how environmental performance of a product can be planned in early stages of NPD, in requirements identification and conceptual design phases.

A development direction presented in the paper is the replacement of structural materials, like metals, wood, glass with composite materials. This was possible a long time ago, with the invention of polymers, as thermoset and thermoplastic synthetic polymers, with comparative properties. In order to increase their strength, they have been reinforced, at first using glass fibre, later carbon fibre and then various natural fibres. Composite materials have become very interesting with their use in the aerospace industry. They have spread quickly in aeronautics, sports equipment's, like tennis rackets, golf sticks, sailing yachts, and also in furniture industry [14]. The first attempts to use in the furniture industry have been known since 1948, with the development of glass fibre-polyester armchairs. This type of material is lightness, colourfulness, easily shaped into complex profiles, accessible. At the "Synthetic by nature" exhibition in April 2015 at Design museum in Gent, Belgium, were exposed over 50 products from flax or hemp fibre reinforced composites [15].

\section{General aspects of the design process}

Designers have always been the ones who change the world. The change occurs as a result of projects related to products or services and/or to machines and technologies for their implementation. The design process consists of a succession of correlated activities designed to generate the conceptual basis for achieving a product. Pugh et. Al, [16] presents a integrated product design model that takes into account all the problems of product development: customer requirements, design specifications, conceptual design, technical design, manufacturing, sales, etc.

A new approach of the innovative products design process, with the main steps and a creativity method are presented in [17]. Starting from the premise that a product is designed to meet a social need, because its users must be satisfied by the product, the designers are the ones who conceive the product, the idea of the product based on its necessity and utility, to an imaginary form, then to a descriptive phase and finally to a model in perspective. We can make a difference between an "artistic" designer and a design engineer. "To create a beautiful, accepted and appreciated form at one point is more an art and less a science. Engineers and designers are called upon to produce beautiful products, both to create human working conditions for those who use them, and to participate forcefully in competition on an international market" [18]. The aspect of a product is a synthesis of the 
art - fashion - medium - technical factors, and for the designer it is a challenge because the product has to satisfy the four basic conditions, useful-beautiful-functional-economical. For these reasons, the approaches of designers and engineers, although different, must have a convergence area in which aesthetic, technical, functional and economic aspects meet. This also results from the constraints that the new product has to satisfy (Figure 1).

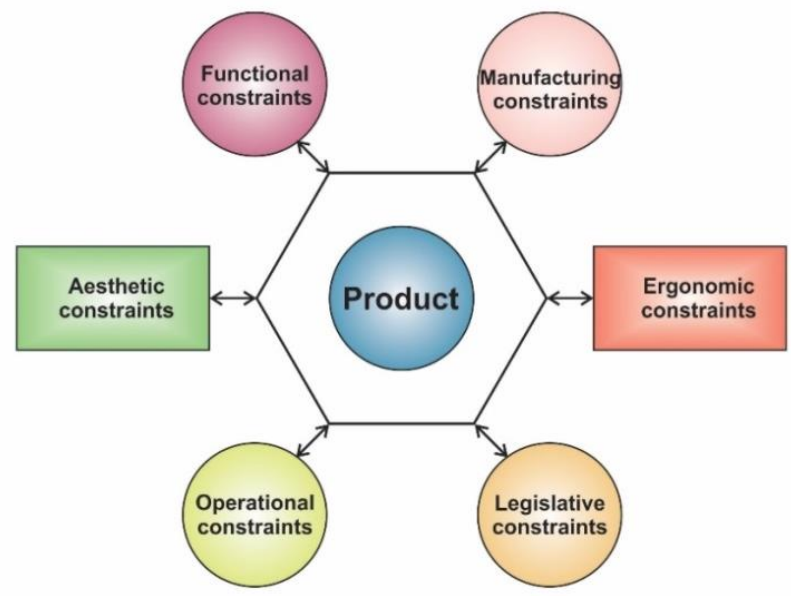

Fig. 1. The constraints on the design of a product.

By a new product we should not always see a "pioneer" product, a product with absolute novelty. The "renewal" of a product may consist in product modernization by changing shape, material, technology or by a new structural conception that gives it complementary or improving product features or socio-economic impact.

In the design of furniture products, the designer has to respect the constraints (requirements) shown in Figure 1. The constraints were established by a market research that addresses both the needs of the users and the existing products. Users' needs were determined by questioning a number of targeted consumers. When making questionnaires, a user-friendly language must be used, not a specialist language. The results by processing information from questionnaires must be transformed into constraints and design data.

Based on market research, product design specifications are developed. The design specifications will also contain legislative constraints or requirements imposed by the standards. The product concept is based on the design specifications resumed in Figure 2.

\section{A method for redesigning components to replace wooden parts with composite materials}

Replacing wood with composite materials involves redesigning the components. Redesigned parts should be analysed in the context of the assembly because their characteristics result from the functionality of the assembly. For every product, if we are going to change the material from which it was originally designed, we have to make a new project. The redesigned part will have to partially respect the shape and dimensions of the original part, at least at the level of the connection with the other components.

Then, in addition to size and shape constraints, the redesigned part must be suitable for manufacturing process by the new material, that is, to respect manufacturing constraints. For example, the shape of a wooden part, in assembly operations can not be preserved identically if it is made of plastics, injection or composite, by thermoforming. 


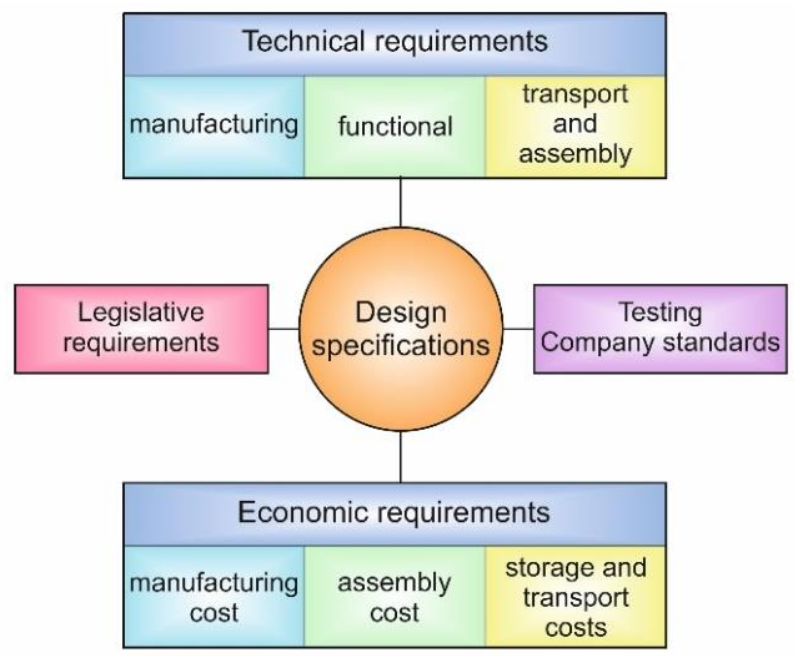

Fig. 2. Design specifications of a product.

The activities flow for furniture design, based on design specifications is shown in Figure 3.

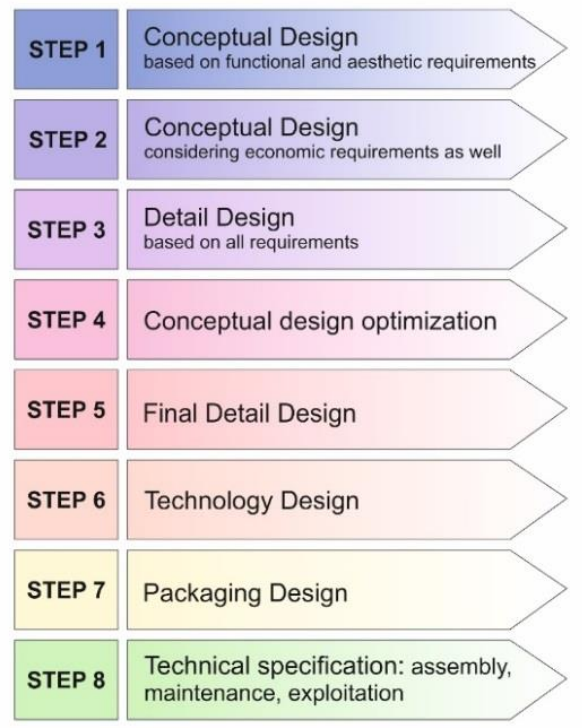

Fig. 3. The activities flow for furniture design.

A cause for which the shape change is needed is in the form of the matrix and the molding process.

There are many furniture products, especially those of the upholstered, which are successful on the market. Replacement of wood with composites in this product category should not be visible to the recipient, their external shape and functionality remaining unchanged. The parts of the resistance structure cannot be kept in their original form, especially due to manufacturing constraints. Then, functionally, the redesigned part must provide the characteristics of the original part. The study of replacing the wooden parts with composite materials based on vegetable fibres in furniture design was presented in paper [19]. 
A method of redesigning the parts by changing wood with composite materials, used for existing products is shown in figure 4.

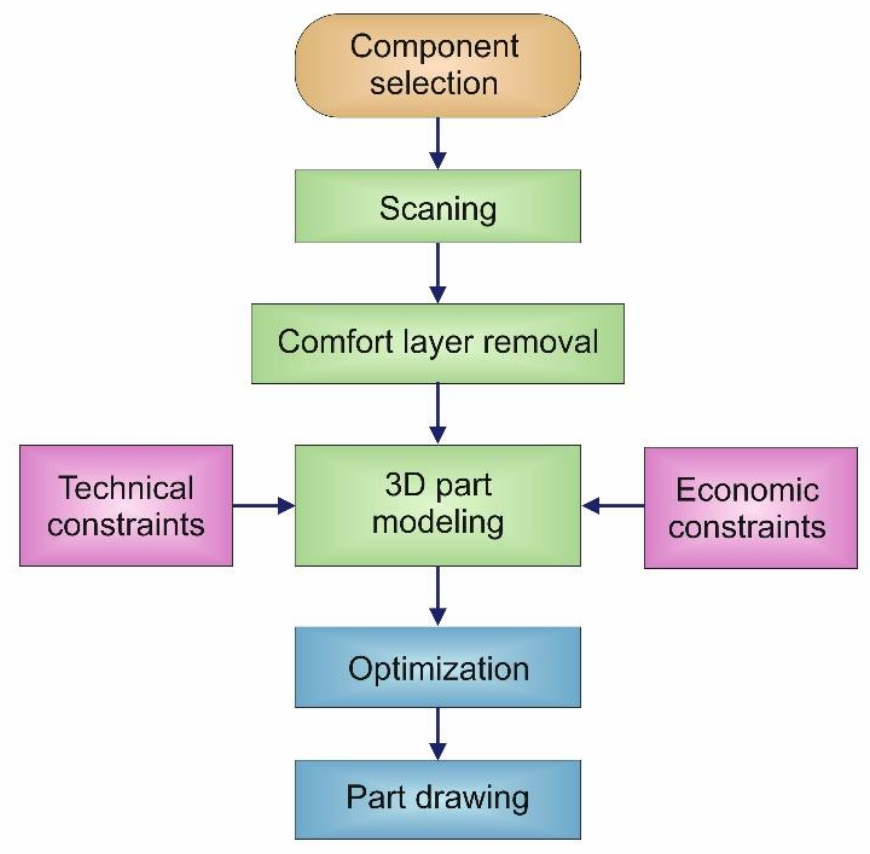

Fig. 4. The method of redesigning the parts.

Scan operation is required only if we do not have the 3D model of the assembly. By removing the comfort layer (generally known its thickness) it is obtain the volume and the outer surface of the part. Because the comfort layer is flexible (deformable), the outer surface of the workpiece should not be the same as that resulting from the removal of the comfort layer. These deviations from the resulting surface allow us to offer the piece a technological form. Thus, the new part will be designed to meet the following requirements:

- Dimensional and shape, to fit the determined volume;

- Functional, to resist the stresses imposed by the tests of the ensemble;

- Manufacturing, meaning to be manufactured under economic conditions.

- After the 3D modelling phase follows an optimization stage aimed at:

- Reducing material consumption by increasing the stiffness of the workpiece using ribs and various cut surfaces, as presented in paper [20]

- Increasing the quality of the parts and productivity through the design of highly feasible forms

- Reduce the manufacturing cost, on all possible ways.

\section{Case study}

Below is a case study to illustrate how the above method was applied (table 1). The selected furniture part is a sofa side, for which $3 \mathrm{D}$ shape can be obtained by scanning it. The next step is to remove the comfort layer, considering its known thickness, to obtain the outer volume of the part. The part volume has to be designed and optimized, to obtain the part drawings for manufacturing. 
Table 1. Case study for a sofa side.

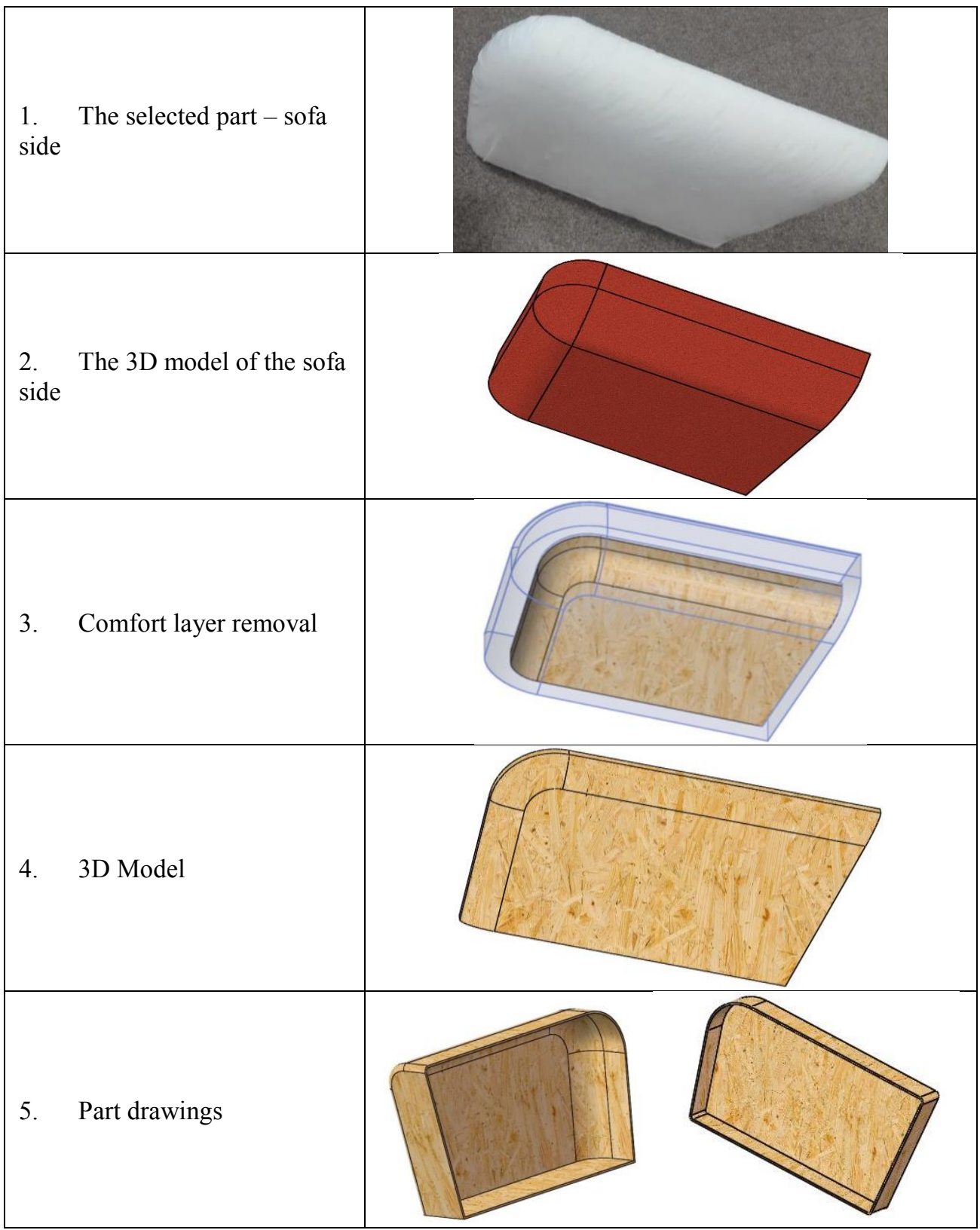

\section{Conclusions}

Based on another model for designing innovative products [17], the authors have developed a new method for redesigning the resistance structure by replacing the wooden parts of upholstered furniture. Generally, designers of upholstered products design, in a first stage, the external shape that gives the appearance and functionality of the furniture, and then deals with the design of the resistance structure and the technological aspects. The method has a general character and can be applied both to upholstery existing products, to which 
we want to change the material of the resistance structure by reverse engineering, as well as for new products.

The method is based on the principle of determining the outer volume of the resistance structure by removing the comfort layer from the total volume of the component. Then, starting from the determined volume, the component's resistance structure is projected from the desired material by subjecting it to the functional and testing constraints of the furniture. Optimization takes into account both technical and economic constraints that the designer considers relevant.

The method was validated by redesigning different wooden components of products manufactured by TAPARO (sofas, chairs and armchairs). The wood was replaced with composite materials that offers the functional requirements of the product as a whole, but can also be replaced by other materials.

\section{References}

1. J.A. Diego-Mas, J. Alcaide-Marzal, International Journal of Industrial Ergonomics 53, 102-114, Spain, (2016)

2. Y. Ko, , Computers \& Industrial Engineering, 107, 345-359, Taiwan, (2017)

3. K.T. Ulrich, S.D. Eppinger, Product design and development, 2 (2000)

4. D. Cavallucci, P. Lutz, In first international Conference on axiomatic design, Proceedings of ICAD, 21-23 (2000)

5. C. Kahraman, T. Ertay, G. Büyüközkan, European Journal of Operational, 171 (2), 390-411 (2006)

6. A. Segismundo, P.A. Miguel, International Journal of Quality \& Reliability Management, 25 (9), 899-912, (2008)

7. G. Altshuller, And suddenly the inventor appeared TRIZ, the theory of inventive problem solving (2nd ed.) (1996)

8. V. Kokotovich, Design Studies, 29 (1), 49-69 (2008)

9. K. Kim, K. Lee, Design Studies, 46, 226-260 (2016)

10. D. Visotsky, A. Patel, J. Summers, The $24^{\text {th }}$ CIRP Conference on Life Cycle Engineering USA, Procedia CIRP 61, 69-74 (2017)

11. H. Wenzel, M.Z. Hauschild, L. Alting, Methodology, Tools and Case Studies in Product Development. Springer Science \& Business Media, 1, (2000)

12. V. Rayate, J.D. Summers, Int. Des. Eng. Tech. Conf. Comput. Inf. Eng. Conf. Chicago (2012)

13. G. Pahl, W. Beitz, Engineering Design: A Systematic Approach, 11, Springer Science \& Business Media (2013)

14. L. Pil, F. Bensadoun, J. Pariset, I. Verpoest, Composites: Part A, 83, 193-205, (2016)

15. *** http://www.Designmuseumgent.Be/ENG/Exhibitions-2015/Synthetic-By Nature Php (2015)

16. S. Pugh, Creating Innovative Products Using Total Design. Addison-Wesley Inc, (1996)

17. C. Ciupan, Proceedings of $5^{\text {th }}$ Int. Conf. on the management of Technological Changes, Alexandroupolis, Greece, 2, 283-288, ISBN 978960-8932-2-9 (2007)

18. A. Toma, Cercetări şi contribuţii privind conexiunea formă, ergonomicitate, funcţionalitate în domeniul maşinilor unelte. Teza de doctorat, UTCN (2012)

19. I. Filip, E. Ciupan, I. Cionca, M. Ciupan, E. Pop, E. Campean, V. Heres, F. Rat, C. Gherghel, Proceedings of the XXI ${ }^{\text {th }}$ Int. Scientific Conf. "INVENTICA 2017, 38-45, (2017)

20. M. Steopan, C. Ciupan, E. Campean, E. Pop, I. Filip, L. Stelea, Proceedings of the $\mathrm{XXI}^{\text {th }}$ Int. Scientific Conference "INVENTICA 2017", 95-103, (2017) 
